\title{
THE PROTECTIVE ROLE OF FLAXSEED LIGNAN IN MALE RABBITS WITH HIGH-FAT DIET: HISTOPATHOLOGICAL STUDY
}

\author{
ZAHRAA AHMED OKHTI ${ }^{a}$, MUTHANNA I. AL-EZZI ${ }^{b}$, RAGHAD ABDULMAHDI $^{b}$ \\ aDepartment of Clinical Laboratory Sciences, College of Pharmacy, Al-Mustansiriyah University, Baghdad, Iraq, ${ }^{b}$ Department of \\ Pharmacology and Toxicology, College of Pharmacy, Al-Mustansiriyah University, Baghdad, Iraq
} Email: muthanna_ibrahem@yahoo.com

Received: 08 Jun 2016 Revised and Accepted: 09 Sep 2016

\begin{abstract}
Objective: The objective of the study was to investigate the effect of dietary flaxseed-derived lignan supplement as anti-hyperlipidemic (fatty liver changes) on rabbit liver.

Methods: Rabbits were assigned randomly into three groups (five rabbits for each group): group-1, normal diet (negative control); group- $2,1.6 \%$ cholesterol diet for $30 \mathrm{~d}$ (positive control) and group-3, $1.6 \%$ cholesterol for $30 \mathrm{~d}$ then gave $40 \mathrm{mg} / \mathrm{kg} / \mathrm{day}$ of pure flax lignan for $14 \mathrm{~d}$.

Results: Marked proliferation of fibrous connective tissue infiltrated with mononuclear cells was recorded; congested dilated of sinusoids and fibrosis in the portal area around the proliferation of bile ducts and congested portal blood vessels with the proteinous material in the lumen of bile ducts were also recorded. In other sections, the liver showed large necrotic area replacement with RBCs as well as enlarged foamy hepatocytes with mononuclear cells in narrowing sinusoids were seen.
\end{abstract}

Conclusion: From the results of this study we can conclude that lignan has been used successfully in decreasing the inflammatory cells in congested blood vessels and sinusoids and has decreased the inflammatory cells infiltration in moderate fibrosis in the portal area around the bile ducts of rabbit liver tissue.

Keywords: Flaxseed Lignan, Secoisolariciresinol, Diglucoside

(C) 2016 The Authors. Published by Innovare Academic Sciences Pvt Ltd. This is an open access article under the CC BY license (http://creativecommons. org/licenses/by/4. 0/) DOI: http://dx.doi.org/10.22159/ijpps.2016v8i11.13323

\section{INTRODUCTION}

Fatty liver disease (FLD) is the most common acquired metabolic disorder associated with insulin resistance and metabolic syndrome (obesity, combined hyperlipidemia, Type 2 diabetes mellitus and high blood pressure), and it is characterized by the presence of hepatic steatosis in the liver tissue $[1,2]$

The presences of hypercholesterolemia cause the collection of cholesterol and triglycerides (neutral fats) within the hepatocytes and demonstrate them as small fat vacuoles (liposomes) around the nucleus (macrovesicular fatty change). FLD is encountered in about $20-35 \%$ of the general adult population in the United States with about $10 \%$ of these advancing toward FLD. In contrast, the prevalence of steatosis in obese individuals is about $75 \%$, and nearly $35 \%$ or more of these, with no evidence of excess alcohol consumption, develop FLD [3, 4]

Moreover, steatosis or fatty liver changes contain a wide range of liver injuries, extending from simple macrovascular steatosis to steatohepatitis, advanced fibrosis, and cirrhosis [5].

Subsets of fatty liver disease which progress to cirrhosis are being increasingly known as the main cause of liver-related morbidity and mortality with the prospect to progress to liver failure [6].

Many studies have provided a new therapeutic strategy to reduce hypertriglyceridemia and fatty liver by Flaxseed supplementation [7].

Flaxseed lignan is believed to be one of the most substantial sources of omega- $3 \alpha$-linolenic fatty acids, Secoisolariciresinol diglucoside (SDG), pinoresinol, matairesinol and lariciresinol, among other seeds because of its ability to work as antioxidant, antiproliferative, antiestrogenic, anti-aromatase and anti-angiogenic activities; its influence on different diseases has been established, including on liver diseases such as fatty liver disease $[7,8]$.
Lignans are a group of polyphenolic compounds in plants that share structural similarities with estrogen and thus have been classified as phytoestrogens. SDG is present in flaxseed in the form of complex polymeric structures, in which it is covalently bound via ester linkages to 3-hydroxy-3-methyl glutaryl (HMG), which it is the ratelimiting enzyme in the cholesterol biosynthetic pathway and its consider as a revolutionary discovery of the dyslipidemia treatment as it effectively lower LDL-C and triglycerides (TG) levels with small increase in HDL-C as well [9-11].

SDG is a recognized nutraceutical; it has been shown to reduce the risk of diabetes, and hormone-related cancer; it has antioxidant activity, cardioprotective effect, and improves renal function in lupus nephritis patients [8].

Lignans exist in different types of nutritious materials, like plant seeds, whole grains, legumes, vegetables and fruits. Flax (Linumusitatissimum) is one of the richest sources of plant lignans. The concentration of lignans in flaxseed was observed to be more than 100 times higher than that in most other foods for example in flaxseed it's about $3699 \mu \mathrm{g} / \mathrm{g}$, sunflower seed $6.1 \mu \mathrm{g} / \mathrm{g}$, peanut legumes $2.73 \mu \mathrm{g} / \mathrm{g}$, blackberry $37.1 \mu \mathrm{g} / \mathrm{g}$ and Broccoli is about $4.14 \mu \mathrm{g} / \mathrm{g}[12,13]$.

To our best knowledge, there is no document about use flaxseed lignan extract as anti-hyperlipidemic agent for fatty liver disease study in Iraq. Therefore, the objective of the study was to investigate the effect of dietary flaxseed-derived lignan supplement as antihyperlipidimic (fatty liver changes) on rabbit liver.

\section{MATERIALS AND METHODS}

\section{Chemicals and Kits}

Chemicals and diagnostic kits used in the study listed in table 1.

\section{Instruments, equipment and apparatus}

Different instruments, apparatus and equipment, have been used in this study and listed in table 2. 
Table 1: Chemicals and diagnostic kits used in the study with their suppliers

\begin{tabular}{ll}
\hline Chemicals and kits & Source (Manufacturer company) \\
\hline Absolute Methanol 99.8\% & BDH (England) \\
Chloroform & BDH (England) \\
Ethanol 96\% & BDH (England) \\
Formalin & Sigma (Germany) \\
Petroleum Ether & BDH (England) \\
Sodium Hydroxide (NaOH) & BDH (England) \\
Cholesterol Kit & Biommaghreb (Tunisia) \\
Triglycerides Kit & Biommaghreb (Tunisia) \\
Cholesterol-HDL Kit & Biommaghreb (Tunisia) \\
\hline
\end{tabular}

Table 2: Instruments, equipment, and apparatus used in the study with their sources

\begin{tabular}{ll}
\hline Equipment name & $\begin{array}{l}\text { Manufacturer } \\
\text { company }\end{array}$ \\
\hline Continuous Extraction Apparatus Soxhlet & Quickfit (England) \\
Centrifuge & Beckman (England) \\
Digital Still Camera & Sony (Japan) \\
Light Microscope & Olympus (Japan) \\
pH-Meter & Radiometer (Denmark) \\
Rotary Evaporator & Buchii (Switzerland) \\
Sensitive Balance & Sartorius (Germany) \\
U. V-Visible Spectrophotometer & Shimadzu (Japan) \\
Vortex & Griffin (England) \\
Water Bath & Gallenkamp (England) \\
\hline
\end{tabular}

\section{Extraction of lignan (SDG oligomers)}

Flaxseed was collected from the local market in Iraq, classified and identified by the botanist Professor Dr. Ali Almosawi in the college of sciences, University of Baghdad. First, cleaning flax from some parts of vegetarian of flaxseed and dust, secondly grinding flaxseeds properly by a grinder machine, eventually obtained a homogenized powder that was ready for extraction. .The extraction was carried out by using soxhlet apparatus with petroleum ether and chloroform respectively for $6 \mathrm{hr}$. defatted flaxseed powder was obtained by removing solvent from the extract on a rotary evaporator under reduced pressure at $40{ }^{\circ} \mathrm{C} .50 \mathrm{~g}$ of the milled and defatted flaxseed powder was accurately weighed and extracted with $300 \mathrm{ml}$ of $70 \%$ aqueous methanol solution with continuous stirring for $4 \mathrm{~h}$ followed by sonication for $10 \mathrm{~min}$ and centrifugation at $10,000 \times \mathrm{g}$ for $5 \mathrm{~min}$ (partial pure). The extraction procedure was repeated three times then The flaxseed extract was subjected to an alkaline hydrolysis (final $\mathrm{NaOH}$ concentration of $20 \mathrm{~m} \mathrm{M}$ ) at $50{ }^{\circ} \mathrm{C}$ for hydrolyzing SDG oligomers (pure lignan, SDG) [14].

\section{Preparation of concentrations of pure lignan}

This process included the preparation of one concentration of pure lignan $(40 \mathrm{mg} / \mathrm{ml})$. This was done by dissolving $(0.04 \mathrm{~g})$ of lignan into $(1 \mathrm{ml})$ of distilled water [15].

\section{Animals}

Data reported a total of 15 male specific pathogen free (SPF) wildtype rabbits. Rabbits were 4 mo old at the beginning of the study and weighed a mean of $1.5 \mathrm{~kg}$. All rabbits were purchased from AboGraib Market (Baghdad). Rabbits were individually housed in plastic cages in temperature and humidity controlled rooms. The light/dark cycle was $12 \mathrm{~L} / 12 \mathrm{~d}-\mathrm{h}$.

\section{Dietary treatment}

After one week of acclimation, animals were divided randomly into three groups (five rabbits for each group) that have been used to study the possible effect of lignan compounds of flaxseed compared to cholesterol-induced liver damage allocated as follows:

Group-I: Rabbits were fed $160 \mathrm{~g} /$ day of a diet (pellet) without cholesterol for $30 \mathrm{~d}$. (The group served as negative control).

Group-II: Rabbits were fed $160 \mathrm{~g} /$ day of a diet (pellet) contain $1.6 \%$ cholesterol for $30 \mathrm{~d}$. (The group served as control positive).

Group-III: Rabbits were fed $160 \mathrm{~g} /$ day of pellet diet that contained $1.6 \%$ cholesterol for $30 \mathrm{~d}$ then were given $40 \mathrm{mg} / \mathrm{kg} /$ day of pure flax lignan for $14 \mathrm{~d}$ (following the $30 \mathrm{~d}$ high cholesterol diet).

\section{Lipid profiles analysis}

Blood was collected by retro-orbital puncture. Blood was allowed to clot for $30 \mathrm{~min}$ at room temperature and subjected to centrifugation at $2000 \mathrm{rpm}$ for $15 \mathrm{~min}$, to obtain serum. The resulting upper serum layer was collected in clean, dry labeled microcentrifuge tubes. This serum was analyzed for serum TG, TC, HDL-C using commercially available kit [15].

Serum LDL-C was determined by the following calculation:

$$
\mathrm{LDL}-\mathrm{C}(\mathrm{mg} / \mathrm{dl})=\frac{\mathrm{TC}-(\mathrm{HDL}-\mathrm{C}+\text { Triglycerides })}{5}
$$

\section{Histopathological examination}

After rabbits have been sacrificed, the liver was removed quickly and placed in containers that contain cool saline to remove excess blood then fixed in containers that contain $10 \%$ formaldehyde solution to prepare tissue sections and then dehydrated in ascending grades of alcohol and embedded in paraffin wax. Sections of 4-6 $\mu \mathrm{m}$ thickness were cut, stained with Hematoxylin and Eosin ( $\mathrm{H}$ and $\mathrm{E}$ ) for then examined for histological changes according to Carleton et al., 1980 [16].

\section{Statistical analysis}

The experiment design used for these studies was Rationalized Complete Block Design (RCBD). The results were presented as means \pm standard deviation (SD). One-way analysis of variance (ANOVA) followed by Tukey test comparison $t$-test (2-tailed) was used to compare between treatments groups. The differences between the means are considered significant at the 0.05 confidence level. The concentration that inhibits $50 \%$ of the blood vessels growth, cells proliferation $\left(\mathrm{IC}_{50}\right)$ this value was analyzed by linear regression equation and logarithmic equation. The statistical analysis was carried out by using SSPS 16.0 for Windows (SPSS Inc, Chicago, IL), The level of significance was set at $P<0.05$ as significant.

\section{RESULTS}

Results in table- 3 showed the mean values of serum lipid profile parameters at day 30 after feeding the high fat diet and before treatment with flax lignan in the different experimental groups. The results showed significantly increased serum total cholesterol, serum triglyceride, high-density lipoprotein and low-density lipoprotein in the group's feed high-fat diet in compared to group I.

Table 3: Lipid profile parameters after feeding the high fat diet and before treatment with flax lignan

\begin{tabular}{|c|c|c|c|c|}
\hline \multirow{2}{*}{$\begin{array}{l}\text { Experimental } \\
\text { Groups }\end{array}$} & \multicolumn{4}{|l|}{ Lipid Profile } \\
\hline & $\begin{array}{l}\text { Serum total cholesterol } \\
\mathrm{mg} / \mathrm{dl}\end{array}$ & $\begin{array}{l}\text { Serum triglyceride } \\
\mathrm{mg} / \mathrm{dl}\end{array}$ & $\begin{array}{l}\text { Serum high density lipoprotein } \\
\text { mg/dl }\end{array}$ & $\begin{array}{l}\text { Serum low density lipoprotein. } \\
\text { mg/dl }\end{array}$ \\
\hline Group I & $55 \pm 2.1$ & $44 \pm 1.3$ & $43.8 \pm 2.2$ & $3 \pm 0.4$ \\
\hline Group II & $1169.5 \pm 40.1^{*}$ & $147.5 \pm 4.9 *$ & $209.7 \pm 63.6^{*}$ & $930.5 \pm 71.1^{*}$ \\
\hline Group III & $1012.5 \pm 79.4^{* *}$ & $255.8 \pm 80.2^{* *}$ & $255.8 \pm 80.2^{* *}$ & $780.3 \pm 62.3^{* *}$ \\
\hline
\end{tabular}

*Significant difference between group I and II, **Significant difference between group I and III, and between II and III, Each value represents mean $\pm \mathrm{SD}, \mathrm{n}=5$ for each group. 
The histopathological sections of the liver of animals in the negative control group showed no histopathological changes (normal appearance) as seen in fig. 1.

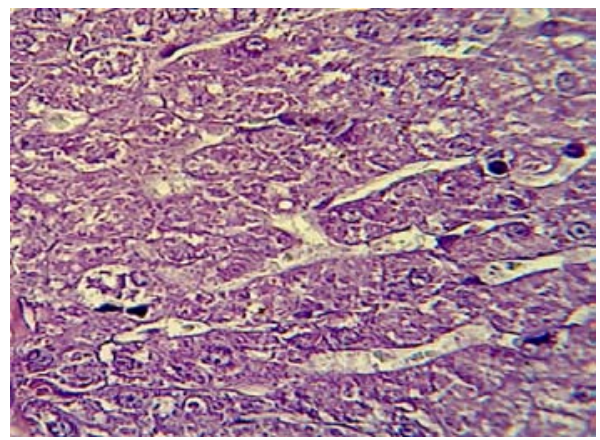

Fig. 1: Histopathological section in liver of animal of the negative control group feed pellet diet without cholesterol, showed normally appearance tissue with no pathological changes, (HandE stain 40X)

Marked proliferation of fibrous connective tissue infiltrated with mononuclear cells around isolated mass of proliferation of hepatocytes without central vein from pseudolobules was marked in induced hypercholesterolemic rabbits in this study (fig. 2).

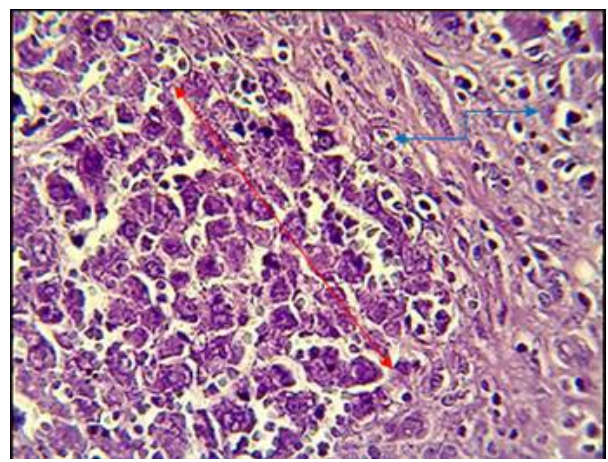

Fig. 2: Histopathological section in liver of animal administration with cholesterol showed marked proliferation of fibrous connective tissue infiltrated with mononuclear cells around isolated mass of proliferation of hepatocytes without central vein (blue arrow), from pseudolobules (red arrow), (H and E stain 40X)

In addition, a marked fibrosis was found to be replacing hepatocytes with congested dilated of sinusoids (fig. 3).

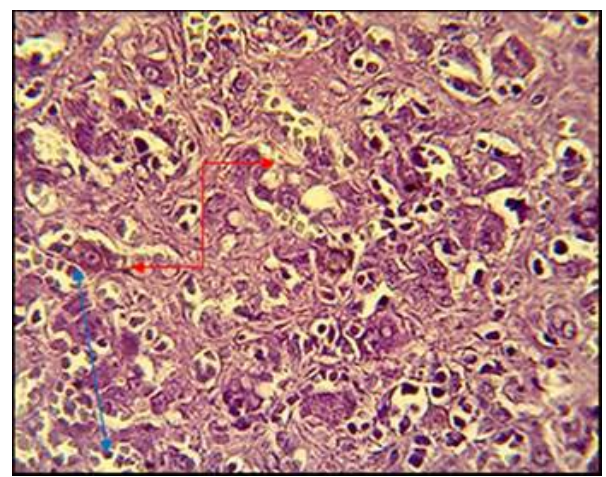

Fig. 3: Histopathological section in liver of animal administration with cholesterol showed marked fibrosis replacement of hepatocytes (red arrow) with congested dilated of sinusoids (blue arrow), (H and E stain 40X)
Furthermore, marked fibrosis in the portal area was found around the proliferation of bile ducts and congested portal blood vessels with the proteinous material in the lumen of bile ducts (fig. 4).

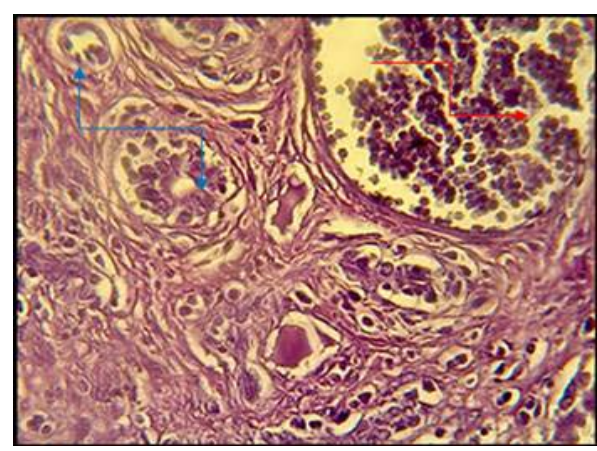

Fig. 4: Histopathological section in liver of animal administration with cholesterol showed marked fibrosis in portal area around proliferation of bile ducts (blue arrow) and congested portal blood vessels (red arrow) with proteinous material in lumen of bile ducts ( $\mathrm{H}$ and $\mathrm{E}$ stain $40 \mathrm{X}$ )

In other sections, the liver showed large necrotic area replacement with RBCs and inflammatory cells in liver parenchyma (fig. 5), as well as marked enlargement foamy hepatocytes (fatty liver) that lead to occlusion of the sinusoids with mononuclear cells in narrowing sinusoids were seen (fig. 6).

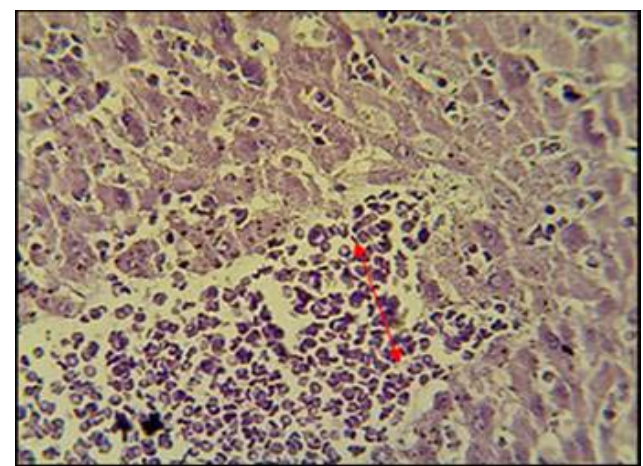

Fig. 5: Histopathological section in liver of animal administration with cholesterol showed large necrotic area replacement with RBCs and inflammatory cells in liver parenchyma (red arrow), (H and E stain 40X)

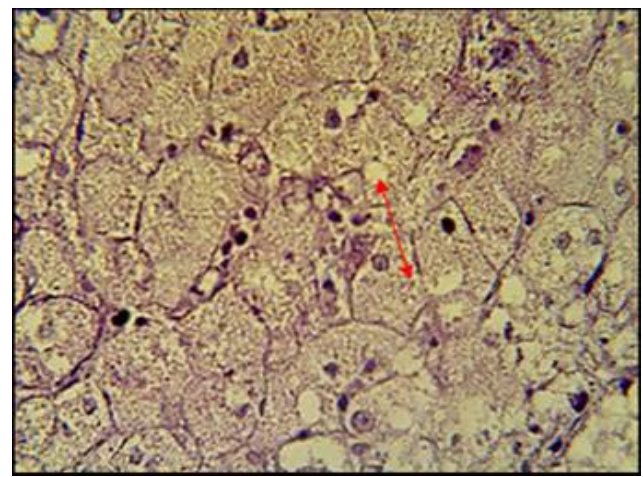

Fig. 6: Histopathological section in liver of animal administration with cholesterol showed marked enlargement foamy hepatocytes that lead to presence of small fat vacuoles (liposomes) around the nucleus (microvesicular fatty change) and occluded of the sinusoids with mononuclear cells in narrowing sinusoids ( $\mathrm{H}$ and $\mathrm{E}$ stain $40 \mathrm{X}$ ) 
In other animals, fibrosis around multiple hepatic masses consisting from necrotic and apoptotic hepatocytes with the proliferation of certain hepatocyte (fig. 7).

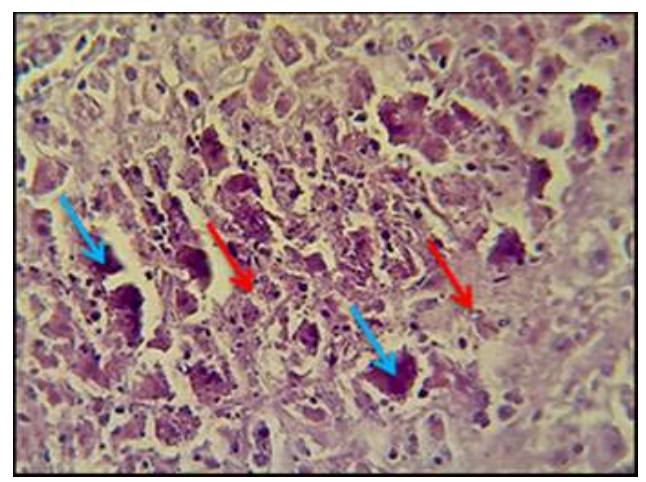

Fig. 7: Histopathological section in liver of animal administration with cholesterol showed fibrosis around multiple hepatic masses (red arrows) consisting from necrotic and apoptotic hepatocytes (blue arrows) with proliferation of certain hepatocytes ( $\mathrm{H}$ and $\mathrm{E}$ stain $40 \mathrm{X}$ )

After treatment with lignan, it was found that there is a moderate amount of inflammatory cells in congested blood vessels and sinusoids (fig. 8) and moderate inflammatory cells infiltration in moderate fibrosis in the portal area around bile ducts (fig. 9).

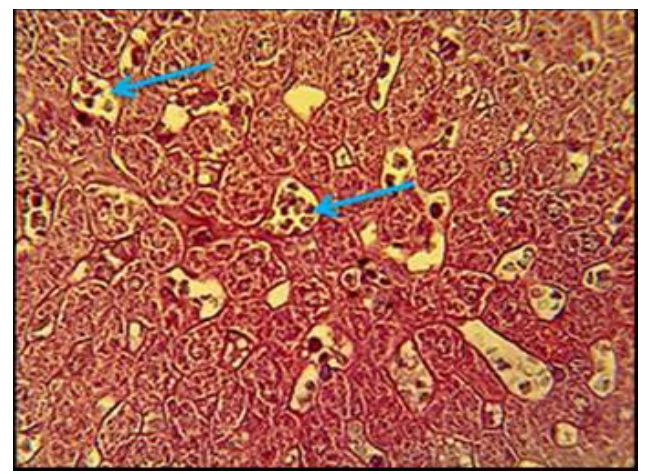

Fig. 8: Histopathological section in liver of animal administration with cholesterol and treatment with lignan showed moderate inflammatory cells, moderate congested blood vessels and sinusoids (blue arrows), (H and E stain 40X)

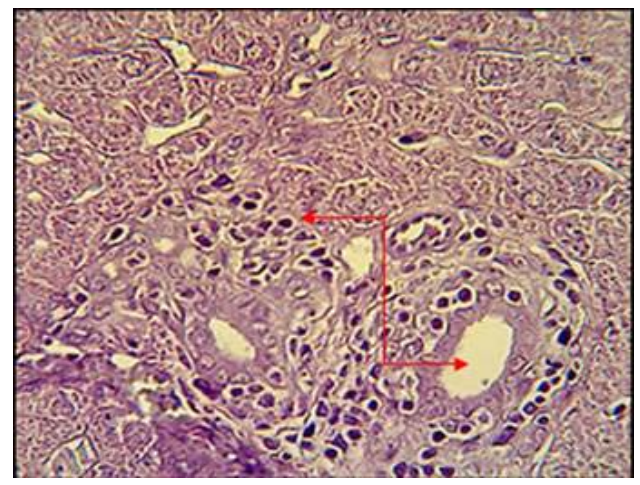

Fig. 9: Histopathological section in liver of animal administration with cholesterol and treatment with lignan showed moderated inflammatory cells infiltration in moderate fibrosis in portal area around bile ducts (red arrow), (H and E stain 40X)

\section{DISCUSSION}

The results in table 1 show increased levels of lipid parameters in groups of animals receiving a high dietary intake of fat, this increase in lipid parameters reflects the changes that occur in the liver tissue of studied animal groups.

One of the most important complications of metabolic syndrome is a fatty liver disease (FLD), which is considered as an essential cause of chronic liver disease [3]. Histological changes in most cases involve perivenular regions of the liver parenchyma and implicate an interfering spectrum of steatosis (abnormal retention of lipids within a cell, fig. 6), steatohepatitis and perisinusoidal or pericellular fibrosis (fig. 3, 4), in some cases leading to cirrhosis (fig. 5). These results of the present study were identical with another study done by Hubscher [17].

In addition, this study was found to be a match with another study revealed hypertrophic hepatocytes, hardly apparent sinusoids with fatty infiltration [18].

The pathogenesis of FLD remains unclear. It is proposed that an aberration in fatty acid and triglyceride metabolism leads to hepatic triglyceride accumulation [19]

Moreover, this study yielded convincing evidence that FLD may be due to the high level of cholesterol concentration and other lipids within the blood and then the increased liver uptake to be oxidized and metabolized in order to decrease these levels in the blood and increase their excretion in the urine and faeces. The liver coordinates in uptake, oxidation and metabolic conversion of free fatty acids, synthesis of cholesterol, phospholipids and triglycerides [16].

Recent studies investigated FLD resulting from high level of cholesterol in the blood lead to precipitate of cholesterol in both arteries and the liver tissue, FLD caused by cholesterol accumulation may be joined by atherosclerosis in the arteries. However, it is unclear whether cholesterol deposition in the liver results in simple first-hit steatosis or whether second-hit inflammation facilitates the progression to steatohepatitis through inflammatory cell infiltration and fibrosis. Therefore, it is unknown if cholesterol deposition leads the liver for further injury as is observed in cases of triglycerideinduced fatty liver [20].

The histological study of induced fatty liver obtained from rabbits fed cholesterol and then treated with pure lignan revealed that there is a moderate inflammatory cell in congested blood vessels and sinusoids (fig. 8) and moderated inflammatory cells infiltration in moderate fibrosis in the portal area around bile ducts (fig. 9). This study is agreed with another study done by (Zanwar et al., 2012) [21] who reported the anti-hyperlipidemic activity of flaxseed supplementation lignan on induced hypercholesterolemic rabbits.

In addition to that this study coincided with the latest study done by (Mohammed et al., 2015) [22] who reported flaxseed lignan do as a useful therapeutic hepato-nephroprotective agent. Flaxseed supplementation may supply a new therapeutic design in order to decrease hypertriglyceridemia and fatty liver in rats. Another study reported that rabbits exposure to SDG lignans for sequential $8 \mathrm{w}$ for appreciating histopathologic evaluation score of fatty liver disease and proposed that SDG lignans can do as defensive agent from liver diseases, also it was approved in this study that the effective compound of SDG play the major role as antioxidant agent leading to inhibition of DNA's replication and lipid peroxidation, in addition, to decreasing the production of reactive oxygen species [23].

Another recent study approved that Flax seeds contain anti-oxidants and have high dietary fiber that can help diabetics by inhibit lipid peroxidation and scavenging of hydroxy radicals. Flaxseed has been recorded as one of the plant materials as cancer-preventive foods. Dietary fibers of flaxseeds contain about $6 \%$ mucilage which has nutritional value. SDG, a plant lignan found in flaxseed, has been found to possess antioxidant properties [24].

\section{CONCLUSION}

From the results of this study, we can conclude that lignan has been used successfully in decreasing the inflammatory cells in congested 
blood vessels and sinusoids and decreased the inflammatory cells infiltration in moderate fibrosis in the portal area around bile ducts of rabbit liver tissue.

\section{CONFLICTS OF INTERESTS}

Declared none

\section{REFERENCES}

1. Cerovic I, Mladenovic D, Jesic R, Naumovic T, Brankovic M, and Vucevic D, et al. Alcoholic liver disease/non $\mathrm{C}$ alcoholic fatty liver disease index: distinguish alcoholic from the non-alcoholic fatty liver disease. Eur J Gastroenterol Hepatol 2013;25:899-904.

2. Bodakhe SH, Gupta SK. Diagnostic methods for non-alcoholic fatty liver diseases alternative to liver biopsy: a review. Asian J Pharm Clin Res 2015;8:54-9.

3. Reddy JK, Rao MS. Lipid metabolism and liver inflammation. II. Fatty liver disease and fatty acid oxidation. Am J Physiol 2006;290:G852-8.

4. Bayard M, Holt J, Boroughs E. Nonalcoholic fatty liver disease. Am Fam Physician 2006;73:1961-8.

5. Angulo P. Nonalcoholic fatty liver disease. $N$ Engl J Med 2002;346:1221-31.

6. Sass DA, Chang P, Chopra KB. Nonalcoholic fatty liver disease: a clinical review. Dig Dis Sci 2005;50:171-80.

7. Saad CT, Précoma DB, Merlini AB, Ioshii SO, Champosk NF. Evaluation of flaxseed effects on non-alcoholic fatty liver disease (NAFLD) in rabbits submitted to a hypercholesterolemic diet. Funct Foods Health Dis 2014;4:442-50.

8. Prasad K. Flax lignan complex slows down the progression of atherosclerosis in hyperlipidemic rabbits. J Cardiovasc Pharmacol Ther 2009;14:38-48.

9. Davin LB, Lewis NG. Dirigentphenoxy radical coupling: advances and challenges. Curr Opin Biotechnol 2005:16:398-406.

10. Singha AK, Chawlab V, Sarafc SK, Keshari A. Different chemical, biological and molecular approaches for antihyperlipidemic therapy with spacial emphases on anti-hyperlipidemic agents of natural origin. J Crit Rev 2014;1:1-9.

11. Abid DA, Soulimane NM, Merzouk H, Narce M. Linseed oil supplementation improves lecithin cholesterol acyltransferase and tissue lipase activities in obese pregnant rats and their offspring. Int J Pharm Pharm Sci 2016;8:194-200.

12. Patel D, Vaghasiya J, Pancholi SS, Paul A. Therapeutic potential of Seco iso lariciresinol glucoside: a plant lignan. Int J Pharm Sci Drug Res 2012;4:15-8.
13. Bhathena SJ, Velasquez MT. The beneficial role of dietary phytoestrogens in obesity and diabetes. Am J Clin Nutr 2002;76:1191-201.

14. Li X, Yuan JP, Xu SP, Wang JH, Liu X. Separation and determination of Seco iso lariciresinol glucoside oligomers and their hydrolysates in the flaxseed extract by high-performance liquid chromatography. J Chromatogr A 2008;1185:223-32.

15. Fossati P, Prencipe L. Serum Triglycerides determined calorimetrically with an enzyme that produces hydrogen peroxide. Clin Chem 1982;28:2077-80.

16. Carleton HM, Drury RA, Wallington EA. Carleton's histological technique. $5^{\text {th }}$ Ed. Oxford University Press: USA; 1980. p. 520.

17. Hubscher SG. Histological assessment of non-alcoholic fatty liver disease. Histopathology 2006;49:450-65.

18. Nawras A Alwan. Effect of chicorium intybus extracts on histological changes in liver and kidney of hypercholesterolemic rabbits. Bas J Vet Res 2009;8:98-107.

19. Matteoni CA, Younossi ZM, Gramlich T, Boparai N, Liu YC, McCullough AJ. Nonalcoholic fatty liver disease: a spectrum of clinical and pathological severity. Gastroenterology 1999;116:1413-9.

20. Kim EJ, Kim BH, Seo HS, Lee YJ, Kim HH, Son HH, et al. Cholesterol-induced non-alcoholic fatty liver disease and atherosclerosis aggravated by systemic inflammation. PLoS One 2014;9:e97841.

21. Zanwar AA, Hegde MV, Bodhankar SL. Antihyperlipidemic effect of flax lignan concentrate in triton induced hyperlipidemic rats. Int J Pharmacol 2012;8:355-63.

22. Imran M, Ahmad N, Anjum FM, Khan MK, Mushtaq Z. Potential protective properties of flax lignan secoisolariciresinol diglucoside. Nutr J 2015;14:71.

23. Fukumitsu S, Aida K, Ueno N, Ozawa S, Takahashi Y, Kobori M. Flaxseed lignan attenuates high-fat-diet-induced fat accumulation and induces adiponectin expression in mice. $\mathrm{Br} \mathrm{J}$ Nutr 2008;100:669-76.

24. Pandey M, kuamar V. Nutraceutical supplementation for diabetes: a review. Int J Pharm Pharm Sci 2011;3:33-40.

\section{How to cite this article}

- $\quad$ Zahraa Ahmed Okhti, Muthanna I Al-Ezzi, Raghad Abdulmahdi. The protective role of flaxseed lignan in male rabbits with high fat diet: a histopathological study. Int J Pharm Pharm Sci 2016;8(11):90-94. 